\title{
A Corpus Based Study on Self-repairs in Chinese English Learners' Oral Production
}

\author{
Xiyue $\operatorname{Sun}^{1 *}$ \\ ${ }^{1}$ School of International Education, Yantai Institute of Technology, Yantai, Shandong, 261400, China \\ *Corresponding author. Email: sunxiyue@yitsd.edu.cn
}

\begin{abstract}
The study of self-repairs in oral performance is not systematic or integrated, in which many issues are still worth being investigated. This paper aims to study the types of self-repairs in Chinese high-proficiency English learners' oral production in Test for English Majors Band Four (TEM-4). In this corpus-based study, qualitative and quantitative methods are both applied for analyzing randomly selected text recordings in SECCL (Spoken English Corpus of Chinese Learners). It is discovered that there is noticeable high amount of self-repairs occurred, the repetition self-repair and replacement self-repair have outnumbered the restructure self-repair, reflecting some of the Chinese students' drawback on English oral performance: They tend to pay more attention on linguistic correct of the language but not the communicative ability. Based on this result, the study gives some advices from three perspectives: to learn to use self-repair marker, to cultivate the logical thinking ability, and to add conjunctions to provide more time for speakers to consider, which should inspire further educational researchers, teachers and students.
\end{abstract}

Keywords: Self-repair, Repetition, Replacement, Restructure.

\section{INTRODUCTION}

Given that human oral speech has the characteristic of instantaneity, which means most of our oral production require on the spot planning, setting up and restructuring, and that results in frequent repairs [1]. Schegloff et al provide a basic structure for repair, that is: trouble source, initiation of repair and the completion of repair, the initiation and completion of repair can be initiated by the trouble source or another recipient, thus researchers have proposed different types of repair [2]. The most influential ones are self-repair (self-initiated or other initiated) and other-repair (self-initiated or other initiated). Analyzing the speeches produced by second language learners, it is discovered that they tend to do a lot of repairs, especially self-repairs. On account of this, this study is committed to research the selfrepairs in Chinese high-proficiency English learners' oral production in TEM-4 (Test for English Majors Band Four).

Theoretically, this research will provide more detailed explanation on cases about Chinese learners' self-repairs from the corpus, thus help us comprehend more about the inner language monitoring system.
Therefore, this study is expected to help benefit the Chinese English learners and provide some advice on Chinese English teaching in terms of speaking.

\section{LITERATURE REVIEW}

\subsection{Definition and Classification of Self-repair}

Quoted Ralph: "Human speech is surprisingly disfluent, marked by frequent starts, stops and restarts". Hence people have the ability of self-plan and selfmonitor for what they have to say and make corresponding repair for the communicative purpose [1]. However, the definition of "repair" is not distinguished from "correction" until Schegloff et al., explaining that "repair" is a broader term than "correction", with occurances involving more than merely 'replacement' or 'correction' [3]. Repair occurances can be found where there are no observable problems, thus serving the role of not only "attempting to make things right" but also trying to get things clear and appropriate [4]. Dealing with same trouble types, the repairs can be initiated by the speaker themselves (self-initiated) or another party (other-initiated). Although many researchers have been focusing on 
other-repair since the move of other recipient is more discernible, one of the earlier central findings bring to light that there is a preference for self-correction, resulting in much more appearance on self-repair over other-repair [5]. According to Schwartz, the self-repair is harder to perceive on account of the problem may be potential and the speaker may covertly address the information [6].

Based on the definition of "repair", Schegloff et al. also put forward a general definition of "self-repair": when the initiator of the problem and the producer of move of repair are both the speakers themselves, this is called "self-repair" [3]. As mentioned above, the repair is probably covert thus barely noticeable, Kromos and Postma proposed the definition of self-repair from a psychological perspective, adding many cases about covert self-repair, making the definition more comprehensive [7]. Subsequently, Rieger proposed about self-repair, classifying it from causes, forms and the initiation devices, which also enriched the definition of self-repair [8].

Apart from above, researchers have also studied the classification of self-repair. Among all the frameworks, the most applied one is from Levelt, who devided selfrepair into Overt self-repair and Covert self-repair Obviously, the overt self-repair is easily noticed and classified, he further devided it into three catagories: Different-information-repair, Appropriateness-selfrepair and Error-repair [9]. Modifying Levelt's model, Kormos add a sub-classification to Differentinformation-repair, including message-abandonmentrepair, inappropriate-information-repair and orderingerror-repair [7]. On the contrary, covert self-repairs are related to "inner speech" thus harder to be classified. Another famous model is from Du Bois, deviding selfrepairs from the aspects of self-repair markers: Mistake editiing (I mean), Claiming editing (well), Nuance editing (rather) and Reference editing (that is) [10]. This model offered some new leads on self-repair classification even though it is not that comprehensive. In addition, domestic researchers also made modifications, but almost all of them are based on the model of Levelt and Kormos.

To sum up, domestic and overseas scholars have all proposed and contributed to the classification of selfrepairs, but still, there is no agreed-upon criterion about the classification of self-repair. The definition and the classification of self-repair has been varying in different research. This study has used the framework of Levelt for reference, building a new model of classification of self-repairs.

\subsection{Previous Research Conducted in Self- repair}

Self-repair has gained increasingly attention in recent years, global researchers have studied about the types, structure and the classification of it, also about the initiation devices, self-repair makers and monitoring self-repair theory.

One corpus-based study from Russian investigated the Russian self-repairs in monologues, dividing Russian self-repair into On-line isomorphic repair, Offline isomorphic repair and repairs from other linguistic levels such as grammar and phonology [11]. Also, there was study specifically researched the self-repair from a morphological aspect, revealing that within-word selfrepair exist in any mono-morphemic languages, and the amount of it is quite large than assumed from earlier studies [12]. Referring to Du Bois' model, Sakita investigated self-repair marker well, illustrating that using well as self-repair is a stance act [13].

Some Chinese scholars also investigated self-repairs from different aspects, Quan and Zheng studied selfrepair markers: well, I mean and maybe by native speakers and Chinese English learners. Qi studied the self-repairs initiation devices and their functions, Zeng investigated self-repairs of teenage Chinese EFL learners, proving both native speakers and second language learners have strong preference for selfinitiated self-repairs [14]. Similar theory has been proven in an Iranian study, and replacing is the most frequently used structure for both Iranian and native students [15]. Most of above scholars, especially Chinese researchers, have offered some pedagogical advices to different extent. A study from Indonesia investigated types and functions of repair strategies from the aspect of English lecturers, providing pedagogical considerations from the teacher's aspect [16].

Hardly any of the studies addressed about the strategies of making self-repairs without interrupt the fluency and cohesion of the discourse. To fill this gap, this research offers some advices.

\section{METHOD}

Since this research is a corpus based study, the corpus called SECCL (Spoken English Corpus of Chinese Learners) has been chosen. It is a corpus recording students' oral performance in a Chinese English test called TEM-4 (Test for English Major, Band 4) from the year 2003 to 2006. TEM-4 oral test is for measuring the English major students' speaking ability including linguistic competence and communicative competence. Three tasks are employed, task 1 is retelling a story after listening for two times; task 2 is an impromptu monologue, the student need to 
talk for 3 minutes after prepareing for 3 minutes; task 3 is a dialogue, students do role-play and talk for 4 minutes after preparing for 3 minutes. Students who take this test are from English major thus considered high-proficiency and well-prepared. Audio and text recordings are included in this corpus and there are 6 columns in each sub-corpus in each year. In each subcorpus, six text recordings from task 1, task 2 and task 3 are randomly selected in the year of 2006, thus form a sample size, totally more than 90,000 words.

In this study, qualitative research method is adopted by using discourse analysis, which is beneficial to understand the speech. Quantitative method is also adopted for monitoring the frequency of each self-repair types.

In this paper, two research questions are to be addressed:

(1) What are the types and frequency of self-repairs do Chinese English learners use?

(2) What are the strategies that we can use to make self-repairs to a better end?

\section{RESULTS}

Based on the model of Levelt and Kormos, this study made some adjustment and proposed a new model. Self-repairs are devided into three types that is Repetition, Replacement and Restructuring. Each type contains sub-types, shown in Table 1.

Table 1. Frequency and Percentage for Each Type of Self-repairs

\begin{tabular}{lll}
\hline Types & Frequency & Percentage \\
\hline Repitition (with-in word) & 104 & $11.72 \%$ \\
Repitition (same info) & 244 & $27.51 \%$ \\
Replacement (grammar) & 215 & $24.24 \%$ \\
Replacement (different info) & 93 & $10.48 \%$ \\
Replacement (lexical) & 131 & $14.77 \%$ \\
Restructure (meaning) & 66 & $7.44 \%$ \\
Restructure (form) & 34 & $7.22 \%$ \\
Total & 887 & \\
\hline
\end{tabular}

Table 2. Total Frequency and Percentage for Type of Self-repairs

\begin{tabular}{lll}
\hline Types & Frequency & Percentage \\
\hline Repitition & 348 & $39.23 \%$ \\
Replacement & 439 & $49.49 \%$ \\
Restructure & 100 & $11.27 \%$ \\
Total & 887 & \\
\hline
\end{tabular}

As we can see from Table 1, there are totally 887 self-repairs within the whole sample size, among them, the Same Information Repetition repair takes up to $27.51 \%$, which is the highest percentage and should be paid attention to. Form Restructure accounts for the least percentage, $7.22 \%$. Table 2 shows the total frequency of the three types of repair, the Replacement repair takes up to $49.49 \%$, and the Repetition repair accounts for $39.23 \%$, Restructure repair, with the lowest proportion of $11.27 \%$, is the least popular type of repair.

\subsection{Repetition Self-repair}

Repetition self-repair can also refer to same information repair in Levelt's model [9]. It is just as its name implies, it occurs when one repeat what one just said.

\subsubsection{With-in Word Repetition}

he... fi... fill the jar with rocks.

You will feel very con, convin, convince and, er..., do something

\subsubsection{Same Information Repetition}

A philosophy, a philosophy professor stood before the desk

the, the, the students agree, er, agree that the, the, the jar is full.

$\underline{H e, h e}$ er, took some, took some peppers 〈pebbles> and put them in, and put them in the jar.

\subsection{Replacement Self-repair}

Replacement self-repair can also refer to error selfrepair, when the speakers monitor their speech and realize there is an error utterance, they will try to replace that utterance into another one.

\subsubsection{Grammar repair}

he take out... he takes out a, an empty glass jar, and he takes some, take some <somer $>$... he took some rocks, put them in the jar

the peppers go, go, went into the open spaces between the rock $\langle$ ro $\rangle$, the, the rocks.

Grammar repair happens when students realize there is a grammar mistake.

\subsubsection{Different information repair}

And then he... the student do... the student agreed that and professor do it again.

And these something, er..., the other thing, like your job, house and car 
maybe we... maybe you can follow me to do vovoluntary works.

Different information repair happens when speaker want to provide a different information.

\subsubsection{Lexical repair}

I was so surprised by his speech <speeching> that I even felt shamed, ashamed of myself.

Lexical errors occur and there happens the lexical self-repair.

\subsection{Restructuring Self-repair}

Restructuring self-repair can be called appropriate self-repair, which means reorganizing the syntactic pattern of the utterance or further explaining the meaning of utterance.

\subsubsection{Restructuring Meaning}

do you think big companies will er... help a guy like you are, I mean a student without any experience.

I think I just work for, er, practice, you know, social practice.

Restructuring meaning happens when speakers need to explain what they just said.

They all have the same spirit, they all have the same interests. I think it's it's good for us.

In this case, this is not different information repair since the student is trying to make the sentence more appropriate by choosing a word that fit the meaning.

\subsubsection{Restructuring Form}

do you think is that... it is necessary?

We can practise our... maybe practise our oral English.

We'll find, when you get to find work you will find that companies are schools that attach great importance to your voluntary work.

Restructuring Form is reorganizing the syntactic pattern the sentence, or adding a word to make the utterance more appropriate.

\section{DISCUSSIONS}

The samples selected from the corpus contained more than 90,000 words, among these samples of the oral test, enormous amount of self-repairs appeared. Reasons for this phenomenon may be that students were in a special situation, they may monitor their behaviours much more often to get a higher score, resulting in more self-repairs. However, high frequency of self-repair may interrupt the flow of the sentence, lead to low fluency and the cohesion of the discourse. As concerned to the oral speaking test, time of the test is limited, large amount of self-repair may result in incompletion of the monologue, in some cases, even there is no error utterance, the repetition occupied the test time, lead to insufficient demonstration of the speakers' competence.

\subsection{Types of Self-repair in Chinese EFL learners}

It is worth noting that among these self-repairs, the proportion of Replacement self-repair has been the highest, Repetition self-repair also takes up a high percentage. According to O'Connor, the language proficiency is highly related to the occurrences of types of self-repair, higher proficiency language uses may tend to use self-repair to make the utterance more appropriate, while low proficiency language users make more error replacement self-repairs [17].

In terms of self-repair, the speakers need to detect the problem, break the sentence flow and then form the repair, and this will influence the fluency of the discourse [18]. As the cases above illustrates, Chinese English learners use a high frequent of self-repairs even though some of the self-repair seriously influenced the fluency of the speech. This may indicate that Chinese students take great value of the correctness of the language, but lack of the competence of doing so. Besides, relatively low occurrences of Restructuring self-repair indicates a low communicative competence.

\subsection{Strategies for making self-repair to better end}

As analysis above illustrates, even relatively highproficiency Chinese English learners can still hardly present fluent and coherent speech, on account of this phenomenon, this study offers some strategies to make self-repair to a better end, that is, to enhance the fluency and cohesion of the discourse.

(1) To learn to use self-repair markers like "well, I mean, let me rephrase, what I meant to say is.....". These markers can not only delay the response time, leaving more time to think what the proper utterance is, but also will not break the fluency of the discourse.

(2) To cultivate the logical thinking ability. Considering the oral test, students need to make utterance within a short time, if their thought pattern can be trained into a logical one, the amount of repetition se-repair and the replacement self-repair will plunge.

(3) Adding conjunctions into the speech may also give the speaker more time to think, in addition, making the discourse more coherent. 


\subsection{Limitations and Suggestions}

This paper studied a corpus that is relatively old from the current years, researchers in the future can make more cutting-edge studies about some recent corpus, or even build their own corpus to study.

Oral test is to some extent different from the natural conversation, therefore more self-repairs may occur than normal discourse, self-repair in natural situations also worth being monitored and researched.

\section{CONCLUSION}

In conclusion, adopting SECCL, the study randomly selects 90 samples of the corpus to do discourse analysis and statistic analysing. This study intends to address two major research questions: firstly, types and frequency of self-repairs used by Chinese English learners; secondly, strategies can be learned for making self-repair to a better end. For this purpose, modifying the framework of Levelt, this study proposes a new model of types of self-repair, that is, Repetition selfrepair, Replacement self-repair and restructuring selfrepair. Based on this model, the study classified the corpus data and make statistical analysis. It is found that Chinese students use high frequency of self-repairs, but only a small amount of them are for the purpose of making utterance more appropriate. Strategies are proposed to help with this situation: learn to make use of some self-repair markers; cultivate the logical thinking ability and learn to add more conjunctions in the discourse.

This study also provides some pedagogical implications, in order to improve the communicative ability, teachers can introduce different, even novel materials, which can rise the interest of the learners, and guide them to practice a more native-like expression.

\section{REFERENCES}

[1] Qi, Yang. "The Self-Repair Initiation Devices and Their Functions in Chinese English Majors' Oral Production." MS thesis. Zhejiang Normal University, 2015.

[2] Liu, Jiangtao. "Self-Repair in Oral Production by Intermediate Chinese Learners of English." Tesl-ej 13.1 (2009): n1.

[3] Schegloff, Emanuel A., Gail Jefferson, and Harvey Sacks. "The preference for self-correction in the organization of repair in conversation." Language 53.2 (1977): 361-382.

[4] Kaur, Jagdish. "Raising explicitness through selfrepair in English as a lingua franca." Journal of pragmatics 43.11 (2011): 2704-2715.
[5] Quan, Lihong, and Yanmei Zheng. "A Study of Self-repair Markers in Conversation by Chinese English Learners." Journal of Language Teaching \& Research 3.6 (2012).

[6] Schwartz, Joan. "The negotiation for meaning: Repair in conversations between second language learners of English." Discourse analysis in second language research (1980): 138-153.

[7] Kormos, Judit. "A new psycholinguistic taxonomy of self-repairs in L2: A qualitative analysis with retrospection." Even Yearbook, ELTE SEAS Working Papers in Linguistics 3 (1998): 43-68.

[8] Rieger, Caroline L. "Repetitions as self-repair strategies in English and German conversations." Journal of pragmatics 35.1 (2003): 47-69.

[9] Levelt, Willem JM. "Monitoring and self-repair in speech.” Cognition 14.1 (1983): 41-104.

[10] Quan, Lihong, and Martin Weisser. "A study of 'self-repair'operations in conversation by Chinese English learners.” System 49 (2015): 39-49.

[11] Podlesskaya, Vera I. "A corpus-based study of self-repairs in Russian spoken monologues." Russian Linguistics 39.1 (2015): 63-79.

[12] Fox, Barbara A., et al. "Morphological self-repair: Self-repair within the word." Studies in Language. International Journal sponsored by the Foundation "Foundations of Language" 41.3 (2017): 638-659.

[13] Tomoko I. Sakita. "Self-repair and self-monitoring with the editing term well in narrative in view of stance." Doshisha Global and Regional Studies Review 9 (2017): 1-27.

[14] Zeng, Simin. "Second Language Learners' Strong Preference for Self-initiated Self-repair: Implications for Theory and Pedagogy." Journal of Language Teaching and Research 10.3 (2019): 541-548.

[15] Emrani, Fateme, and Mozhgan Hooshmand. "A Conversation Analysis of Self-Initiated Self-Repair Structures in Advanced Iranian EFL Learners." Online Submission 13.1 (2019): 57-76.

[16] Rido, Akhyar, et al. "Repair Strategies in English Literature Lectures in a University in Indonesia." TEKNOSASTIK 19.1 (2021): 14-23.

[17] O'Connor, Nadine. "Repairs as indicative of interlanguage variation and change." Georgetown University round table in languages and linguistics (1988): 251-259.

[18] Casteele, An Vande, and Katja Lochtman. "SelfRepair in Language Learners' Oral Discourse." Fremdsprachenvermittlung zwischen Anspruch und Wirklichkeit: Ansätze-Methoden-Ziele (2016): 175. 